\title{
Beş Kademeli Modifiye Bardenpho Prosesi ile Atıksulardan Azot ve Fosfor Giderimi
}

\author{
Yağmur UYSAL ${ }^{1 *}$, Berkin ÜSTÜNYILDIZ ${ }^{2}$
}

\author{
Kahramanmaraş Sütçü İmam Üniversitesi Mühendislik-Mimarlık Fakültesi Çevre Mühendisliği, \\ Kahramanmaraş, Türkiye
}

\begin{abstract}
ÖZET: Bu çalışmada evsel atıksuların arıtımında azot ve fosfor gibi nütrienlerin giderimi için laboratuvar ortamında kurulan pilot ölçekli Beş Kademeli Modifiye Bardenpho Prosesi 4 ay boyunca işletilerek arıtım etkinliği araştırılmıştır. Çalışmada kullanılan Bardenpho prosesiyle nitrifikasyon-denitrifikasyon ile azot gidermine ek olarak ortama beşinci anaerobik (havasız) bölüm eklenerek fosfat giderimi de gerçekleştirilmiştir. Kullanılan reaktör laboratuvar ölçekli olup, 60x90x20 cm ebatlarında plexiglass malzemeden imal edilmiştir. Toplam $74 \mathrm{~L}$ hacminde olan reaktördeki her bölme arasında $1 \mathrm{~cm}^{2}$ genişliğinde delikler olup atıksuyun geçişi bu deliklerden kaskat tipinde kademeli olarak sağlanmıştır. Çalışmada laboratuvar ölçekli Beş Basamaklı Modifiye Bardenpho prosesinde evsel atıksu arıtımı yapılmış ve reaktörün yedi bölgesinden (giriş tankı, anaerobik hazne, 1.anoksik hazne, 1.aerobik hazne, 2.anoksik hazne, 2.aerobik hazne, çöktürme tankı) dört ay boyunca haftada iki defa olmak üzere alınan numunelerle sistemin performansı takip edilmiştir. Numunelerde KOİ, $\mathrm{NH}_{3}-\mathrm{N}, \mathrm{NO}_{3}-\mathrm{N}, \mathrm{NO}_{2}-\mathrm{N}, \mathrm{PO}_{4}$, AKM analizleri ve pH, sıcaklık, çözünmüş oksijen (Ç.O.) ölçümleri yapılmıştır. KOİ, $\mathrm{NH}_{3}-\mathrm{N}, \mathrm{NO}_{3}-\mathrm{N}, \mathrm{NO}_{2}-\mathrm{N}$, $\mathrm{PO}_{4}$ için en yüksek giderim verimleri sırasıyla \%98,6, \%95, \%83,3, \%90, \%70,6 olarak belirlenmiştir. Elde edilen verimler literatürle karşılaştırıldığında sistemin iyi bir biyolojik arıtım ve nütrient giderimi gerçekleştirdiği görülmüştür.
\end{abstract}

Anahtar Kelimeler: Atıksu arıtımı, Azot giderimi, Bardenpho Prosesi, Fosfor giderimi, Nutrient giderimi

\section{Nitrogen and Phosphorus Removal from Wastewater by Using Modified Five-Stage Bardenpho Process}

ABSTRACT: In this study, we aimed to investigate nutrient removal efficiency of a pilot scale 5-Stage Modified Bardenpho Process set in the laboratory from wastewater. Phosphorus removal was also occured in this system with adding of an anaerobic stage before nitrification-denitrification process. It was used a plexiglass reactor in the mesions of $60 * 90 * 20 \mathrm{~cm}$, and $74 \mathrm{~L}$ volume. This reactor was segmented into five stages (anaerobic, first anoxic, first aerobic, second anoxic, second aerobic) connected to each other. Water samples collected from the influent, stages and effluent of Bardenpho process to determine system performance were analyzed for $\mathrm{COD} \mathrm{NH}_{3}$ $\mathrm{N}, \mathrm{NO}_{3}-\mathrm{N}, \mathrm{NO}_{2}-\mathrm{N}$ and $\mathrm{PO}_{4}-\mathrm{P}$. It was found that this system was quite effective to remove organic matters and inorganic nutrients from wastewater with high percentage removal rates of 98.6, 95, 83.3, 90 and $70.6 \%$, respectively.

Keywords: Wastewater treatment, nitrogen removal, Bardenpho Process, Phosphorus removal, nutrients

\section{GİRIŞ}

Evsel atıksular, kentlerde temiz suların çeşitli şekillerde kullanılmasıyla oluşan ve kanalizasyon sistemleriyle uzaklaştırılan atıksulardır. Arıtma tesislerinin dizayn edilmesi ve işletilmesi için atıksuyun miktarının, özelliklerinin ve kaynağının bilinmesi gereklidir. Atıksular evsel ve endüstriyel kaynaklardan, yağmur sularından ve okul, hastane gibi hizmet sektörlerinden kaynaklanır. Atıksuyun miktarı kanalizasyon sistemine bağlanan alanın nüfusuna, atıksuyun özellikleri ise bu alandaki nüfusun yaşam standartlarına bağlıdır [1], [2].

Evsel atıksu bünyesinde çok sayıda farklı madde bulunmakta olup atıksuyun karakterinin belirlenmesi için çeşitli parametrelerin ölçülmesi gerekir. Bunların belirlenebilmesi maksadıyla fiziksel, kimyasal, biyolojik ve bakteriyolojik deney ve yöntemlerden faydalanılır. Evsel atıksular biyolojik olarak parçalanabilen maddeleri fazlasıyla ihtiva ettiğinden biyolojik arıtım için oldukça uygundur. Önceleri biyolojik arıtma ile yalnızca karbon giderimi yapılmaktayken günümüzde evsel atıksularda bulunan azot ve fosfor gibi besi elementlerinin alıcı ortama direkt deşarjının da, ötrafikasyon gibi istenmeyen durumlara yol açtığ gözlenmiştir. $\mathrm{Bu}$ yüzden mevcut arıtma yöntemlerine modifikasyonlar uygulanarak karbon giderimine ilaveten nütrient giderimi gerçekleştiren sistemler geliştirilmiştir [3].

Biyolojik antma sırasında atıksuyun içinde bulunan askıdaki kolloidal veya çözünmüş organik maddeler bakterilerce parçalanarak son kararlı ürünlere dönüştürülür. Biyolojik arıtma yöntemleri oksijen varlığında ve yokluğunda işletilen Aerobik Prosesler (Aktif çamur sistemi, havalandırmalı 
lagün, damlatmalı filtre, biyofilm prosesler vb) ve Anaerobik Prosesler (Askıda büyüyen, bağlı büyüyen, çamur yataklı, hibrit sistem, anaerobik lagün) olmak üzere 2 gruba ayrılır.

Biyolojik nütrient giderim prosesleri, atıksuda bulunan azot ve fosforun giderimi için geliştirilen, anoksik, aerobik ve anaerobik fazların kullanıldığ 1 aktif çamur prosesinin farklı modifikasyonlarıdır. Literatür çalışmalarında atıksuyun kirletici özelliklerine bağlı olarak daha iyi kalitede arıtım yapabilmek amacıyla çeşitli konfigürasyonlar oluşturulmuştur. Evsel atıksuların ise biyolojik arıtımı literatürde önem kazanmış olup karbon ve nütrient giderimini sağlamak amacıyla çeşitli konfigürasyonlarda sistemler üzerinde araştırmalar yapılmıştır. Öne çıkan sistemler $\mathrm{A}^{2} \mathrm{O}$, UCT, Bardenpho, VIP, Johannesburg ve ardışık kesikli reaktörlerdir [4].

Atıksu arıtma tesislerinin çıkış suyunda toplam azot (TN) çok düşük konsatrasyonlara indirilmesi gerektiğinde çözünmüş organik azot önemli bir parametre haline gelmektedir [5]. İnorganik azot başarıyla giderilebildiğinden, çözünmüş organik azot ve kolloidal azot düşük TN konsatrasyonuna ulaşabilmek için en önemli engeller olarak görülmektedirler [6]. Biyolojik arıtımda C:N oranının yeterli seviyede olmaması durumunda daha iyi bir azot giderimi sağlanması için ilave organik karbon ilavesi yapılmaktadır. Organik karbon ilavesi çoğu durumda istenilen azot deşarj standartını sağlamak için avantaj olmaktadır. Ancak çözünmüş mikrobiyal ürünlerin (SMP) oluşumu karbon miktarıyla doğru orantılı olarak arttığından, organik karbon ilavesi gerektiren durumlarda $\mathrm{C}: \mathrm{N}$ oranının SMP üzerindeki etkileri araştırılmalıdır [7]. Biyolojik arıtımda optimum çamur yaşının (SRT) SMP üretimini minimize ettiği gözlenmiştir. Aerobik prosesler için optimum çamur yaşı 2 ila 15 gün arasındadır [8].

Fosfor, sularda ötrofikasyona neden olan önemli nütrientlerden birisidir. Alum ve demir tuzları ile gerçekleştirilen kimyasal arıtma fosfor gideriminde kullanılan en yaygın teknolojidir. Ancak son yıllarda birçok biyolojik fosfor giderim prosesleri geliştirilmiştir. Biyolojik fosfor gideriminin en önemli avantajları, kimyasal maliyetini yok etmesi ve kimyasal arıtıma göre daha az çamur oluşumudur. Biyolojik fosfor giderimi atıksuda bulunan fosforun, mikroorganizmaların hücre yapısına katılmasıyla ve son çöktürme tankında çamurla birlikte sudan ayrılmasıyla gerçekleştirilmektedir. Böylece çıkış suyunda istenilen fosfor konsantrasyonuna ulaşılabilmektedir. Fosfor özellikle bazı mikroorganizmaların yapısında fazladan birikmektedir. Bu tür mikroorganizmalara PAO (Phosphorus accumulating organisms) yani fosfor biriktiren organizmalar denmektedir. En çok bilinen türü Acinetobacter'dir. PAO'lar aerobik hetetroflardır ve biyolojik fosfor giderim kapasitesi askıda katı maddedeki bu organizmaların oranına bağlıdır. İyi bir fosfor giderimi için bu tür bakterilerin gelişmesi sağlanmalıdır. PAO'lar aerob oldukları için anaerobik şartlarda çoğalma gerçekleştiremezler. Bunun yerine ortamdaki uçucu yağ asitlerini (UYA) depolarlar ve ağırlıklarını arttırırlar. $\mathrm{Bu}$ amaçla diğer bakterilerle yarışı avantajlı hale getirmek için aerobik ya da anoksik tank öncesi bekleme süresi 0,5-1,0 saat olan bir anaerobik tank tasarlanmaktadır [9].

Bu çalışmada kullanılan sistem olan Bardenpho prosesi nitrifikasyon-denitrifikasyon ile azot gidermekle beraber fosfatı da gidermektedir. Prosese anaerobik (havasız) bölüm eklenerek Beş Basamaklı Modifiye Bardenpho prosesi oluşturulmuş böylece fosfor giderimi de yapılmaya başlanmıştır. Beş basamaklı sistemde havalı, havasız ve anoksik bölümler fosfor, azot ve karbon gideriminde rol oynarlar. İkinci anoksik bölüm, aerobik bölümde oluşan nitratı elektron alıcı, içsel organik karbonu ise elektron verici olarak kullanıp ilave denitrifikasyon sağlar. Son havalı bölüm ise kalıntı azot gazını çözeltiden sıyırmak ve son çöktürücüde fosfor açığa çıkmasını en aza indirmek için kullanılır. Sıvı karışım birinci aerobik bölümden anoksik bölüme geri beslenir [10]. Tanklarda gerçekleşen işlemler sirasiyla:

1. Anaerobik Tank: Havasız ortamın sağlandığ bu tank fosfor gideren bakterilerin sistemde gelişebilmesi için kullanılır. Bu bakterilerin önemli bir özelliği, büyümeleri için gerekli olan fosfor miktarından daha fazlasını bünyelerine alabilmeleridir. Anaerobik şartlar altında bakteriler suya fosfor bırakır, aerobik şartlardaysa sudan fosfor alırlar.

2. I. Anoksik Tank: Heterotrofik bakteriler çözünmüş oksijen yerine nitrat kullanmak suretiyle KOİ/BOİ oksidasyonunu sağlar. Denitrifikasyon sürecinde nitrat azota (gaz) indirgenir.

3. I. Aerobik Tank: Bu aşamada, anoksik havuz çıkışı aerobik tanka verilerek geri kalan KOİ/BOİ de burada heterotrofik bakterilerce oksidasyona uğrar. Sisteme gereken çözünmüş oksijen, kabarcıklı ya da yüzey havalandırma yöntemiyle verilir. Ototrofik bakteriler amonyağı okside ederek sırasıyla nitrit ve nitrata dönüștürür.

4. II. Anoksik Tank: İlk aerobik tanktan anoksik tanka geri devir ettirilmeyen nitratlar bu tankta denitrifiye edilirler. 
Ortamdaki karbonlu organik maddeler nitrattaki oksijen kullanılarak okside edilirler ve nitrat azot gazına dönüştürülerek atmosfere salınırlar. Bu tanktaki nitrat konsantrasyonu I. anoksik tanka göre daha düşüktür. Karbon kaynağı olarak içsel bozunma kullanılır.

5. II. Aerobik Tank: Son aerobik tankta mikroorganizmalar karbon oksidasyonuna devam ederler. Uygun koşullar bulunduğundan PHB (Poli-hidroksibütrat) polimerlerini okside edip elde edilen enerjiyle atıksudan hücre içine Fosfat alımı devam ettirilir. Tank içerisinde anaerobik ortam oluşmasını engellemek için gerekli oksijen sisteme kazandırılır. Bu şekilde hücre içindeki fosforun tekrar dışarı çıkması engellenir. Oluşan azot gazı $\left(\mathrm{N}_{2}\right)$ bu tankta atmosfere verilir.

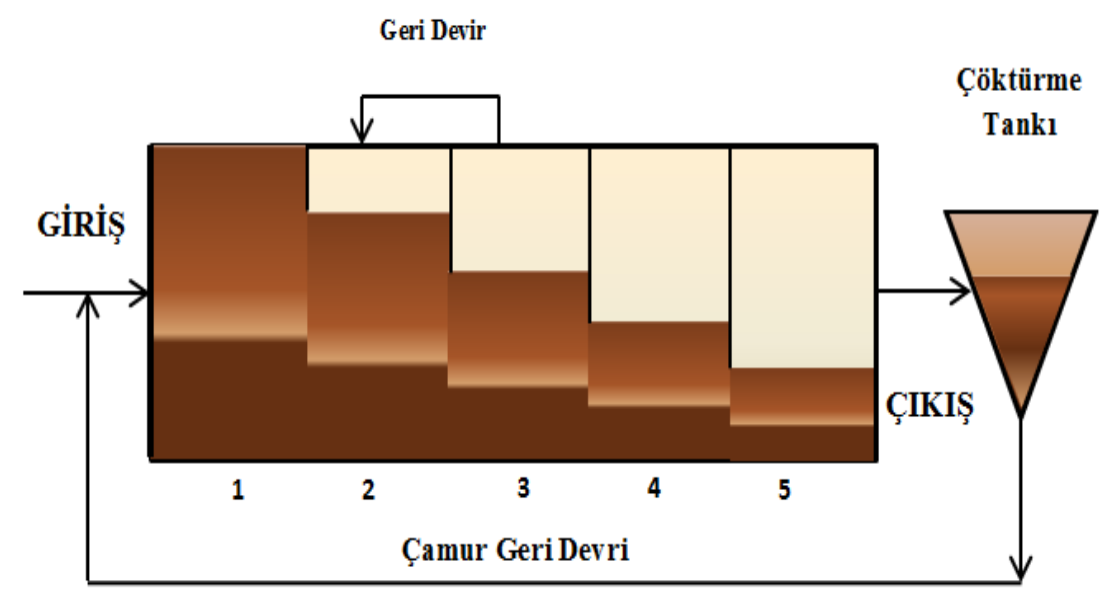

Şekil 1. Beş Basamaklı Modifiye Bardenpho Prosesi Akım Şeması (1-Anaerobik, 2- I. Anoksik, 3- I. Aerobik, 4- II. Anoksik, 5- II. Aerobik)

Burada gerçek evsel atıksu ile sistem kurulmuş olup, sonrasında kullanılacak atıksu sentetik olarak laboratuvarda hazırlanarak sistemin kontrolü bu sayede kolaylaştırılmıştır. Sisteme belli zaman sonra ilave karbon kaynağ1 olarak asetik asit eklenmiş başlangıçtaki ve sonraki fosfor giderim verimleri karşılaştırılmıştır. Laboratuvar ölçekli böyle bir proses tasarımı ender olduğundan literatüre önemli bir kaynak oluşturabileceği düşünülmektedir.

\section{MATERYAL METOT}

Çalışmada kullanılan pilot Bardenoho sistemini işletime almak için öncelikle Gaziantep GASKİ arıtma tesisinden alınan atıksu ile mikroorganizma büyümesi ve gelişmesi sağlanmıştır. Sonrasında çalışmanın stabil şartlarda ilerlemesi için sistem sürekli olarak sentetik atıksu ile beslenmiştir. Çalışmada kullanılan sentetik evsel atıksu bileşimi Tablo 1' de verilmiş olup, atıksu günlük besleme için 30 L 'lik tank içerisinde çeşme suyu ile seyreltilerek hazırlanmıştır.

\subsection{Laboratuvar Ölçekli Bardenpho Reaktörünün İşletilmesi}

Çalışmada evsel atıksuyun Beş Basamaklı Modifiye Bardenpho prosesiyle arıtımı incelenmiștir. Kullanılan reaktör laboratuvar ölçekli olup, 60x90x20 cm ebatlarında plexiglass malzemesinden imal edilmiştir. Toplam 74 L hacminde olan reaktördeki her bölme arasında $1 \mathrm{~cm}^{2}$ genişliğinde delikler olup atıksuyun geçişi bu deliklerden kaskat tipinde kademeli olarak sağlanmıştır. Sırasıyla 1.bölme Anaerobik kısım 22 L, 2.bölme I. Anoksik 13,5 L, 3.bölme I. Aerobik 16 L, 4.bölme II. Anoksik 10,5 L, 5.bölme II. Aerobik 12 L hacminde dizayn edilmiştir. Aerobik haznelerdeki bakteriler için gerekli oksijen hava pompaları vasıtasıyla sağlanmıştır. İç sirkülasyonu sağlamak amacıyla aerobik haznelerden anoksik haznelere çamur hacimce \%20/gün oranında geri devrettirilmiştir. $\mathrm{Bu}$ sayede anoksik haznelerde gerçekleşen denitrifikasyon reaksiyonlarının devamlılığı sağlanmıştır. Son çöktürme haznesindeki çamur belirli zaman aralıkları ile aerobik gözlerdeki mikroorganizma konsantrasyonunun stabil tutulabilmesi için sistem içerisine geri devir ettirilmiştir. Sistem 4 ay süreyle düzenli olarak işletilmiştir. 
Tablo 1. Çalışmada Kullanılan Sentetik Evsel Atıksu Bileşimi

\begin{tabular}{|c|c|}
\hline KİMYASAL & MÍKTAR (g/L) \\
\hline $\mathrm{CH}_{3} \mathrm{COONa}$ & 82 \\
\hline $\mathrm{NaHCO}_{3}$ & 21 \\
\hline $\mathrm{NH}_{4} \mathrm{Cl}$ & 6.88 \\
\hline $\mathrm{KH}_{2} \mathrm{PO}_{4}$ & 2,4 \\
\hline $\mathrm{FeCl}_{3} .6 \mathrm{H}_{2} \mathrm{O}$ & 12,5 \\
\hline $\mathrm{CaCl}_{2} \cdot 2 \mathrm{H}_{2} \mathrm{O}$ & 12,5 \\
\hline $\mathrm{KCl}$ & 5 \\
\hline $\mathrm{MgSO}_{4} .7 \mathrm{H}_{2} \mathrm{O}$ & 25 \\
\hline $\mathrm{NaCl}$ & 25 \\
\hline
\end{tabular}

\section{2. Ölçüm Yöntemleri}

Çalışmada Beş Basamaklı Modifiye Bardenpho Prosesinin her bölmesinden haftada 2 defa olmak üzere numuneler alınmış ve atıksu analizleri yapılmıştır. Alınan numunelerde KOİ, $\mathrm{NH}_{3}-\mathrm{N}, \mathrm{NO}_{3}$ $\mathrm{N}, \mathrm{NO}_{2}-\mathrm{N}, \mathrm{PO}_{4}, \mathrm{AKM}$ analizleri yapılmış ve sistem pH, sıcaklık, çözünmüş oksijen (Ç.O.) parametreleri açısından sürekli kontrol altında tutulmuştur. Tüm analizler Standart Metotlarda [11] belirtilen yöntemlere göre gerçekleştirilmiştir.

- $\mathrm{pH}$ ölçümlerinde, WTW Multiline P4 marka $\mathrm{pH}$ metre kullanılmıştır.

- Ç.O. ve sıcaklık WTW Oxi 3205 marka cihaz ile ölçülmüştür.

- $\quad \mathrm{KOİ}$, nitrit, nitrat ve fosfat parametrelerinin ölçümü HACH/DR $5000 \quad(\mathrm{HACH}$ Company, ABD) Spektrofotometrede gerçekleştirilmiştir

\section{BULGULAR VE TARTIŞMA}

Çalışmada laboratuvar ölçekli Beş Basamaklı Modifiye Bardenpho prosesinde evsel atıksu arıtımı yapılmıştır. Reaktörün yedi bölgesinden (giriş, anaerobik, 1. anoksik, 1. aerobik, 2. anoksik, 2. aerobik, çöktürme tankı) dört ay boyunca, haftada iki defa olmak üzere numuneler alınmış ve sistemin arıtım performans1 KOİ, $\mathrm{NH}_{3}-\mathrm{N}, \mathrm{NO}_{3}-\mathrm{N}, \mathrm{NO}_{2}-\mathrm{N}$, $\mathrm{PO}_{4}-\mathrm{P}$ ve AKM analizleri yapılarak takip edilmiştir. Ham atıksu ve çıkış konsantrasyonları dikkate alınarak giderim verimleri hesaplanmıştır.

\subsection{KOİ Giderimi}

Bardenpho prosesinin giriş ve yedi farklı bölmesinden alınan numunelerin KOİ analizleri yapılmış ve elde edilen sonuçlar Tablo 2' de verilmiştir.

Tablo 2. Bardenpho prosesi boyunca KOİ konsantrasyonlarının değişimi

\begin{tabular}{|c|c|c|}
\hline & KOİ (mg/L) & $\begin{array}{c}\text { Ortalama } \\
\mathbf{( m g / L )}\end{array}$ \\
\hline Giriş & $1310-1120$ & 1196,4 \\
\hline Anaerobik & $1164-696$ & 970,5 \\
\hline 1. Anoksik & $897-214$ & 557,2 \\
\hline 1. Aerobik & $753-114$ & 339,2 \\
\hline 2. Anoksik & $426-54$ & 168,8 \\
\hline 2. Aerobik & $171-21$ & 91 \\
\hline Çık1ş & $88-15$ & 47,6 \\
\hline Verim (\%) & $92-98,6$ & 96 \\
\hline
\end{tabular}

Çalışmadaki ortalama KOİ konsantrasyonlarının değişimi incelendiğinde proseste atıksuyun KOİ konsantrasyonunun reaktör boyunca düştüğü görülmüştür. Akın ve Uğurlu [12] yaptıkları çalışmada en fazla KOİ gideriminin ilk faz olan anaerobik fazda, ikinci olarak anoksik fazda olduğunu ve en düşük giderimin de aerobik fazda gerçekleştiğini belirtilmiştir. Anoksik fazlarda anaerobik faza göre, aerobik fazlarda da anoksik faza göre daha az giderim olmuştur. Yürüttüğümüz çalışmada ise tam tersine sistem sürekli bir KOİ düşüşü gerçekleşmiş ve bir sonraki faz önceki faza oranla giderim verimini artırmıştır. Çıkış atıksuyu baz alındığında sistemin toplan KOİ giderim verimi \%96 olarak bulunmuştur. $\mathrm{Bu}$ da beş basamaklı Bardenpho prosesinin KOİ gideriminde oldukça başarıl olduğunu göstermiştir. 


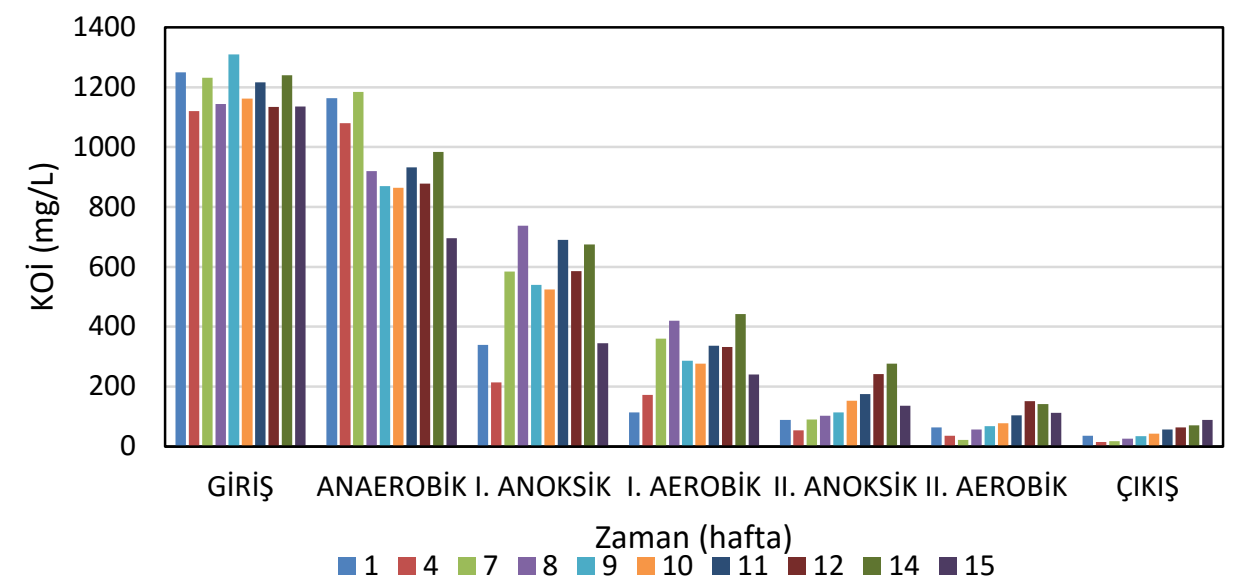

Şekil 2. KOİ konsantrasyonlarının Bardenpho Prosesi boyunca değişimi

\subsection{Azot Giderimi}

Beş Basamaklı Bardenpho prosesi azot ve fosfor nütrientlerini gideren bir sistem olduğundan azot kontrol edilmesi gereken en önemli parametrelerden biridir. Çalışmada reaktörlerdeki azot bileşiklerinin kontrolü prosesin her bölmesinden alınan numunelerde yapılan $\mathrm{NH}_{3}-\mathrm{N}$, $\mathrm{NO}_{3}-\mathrm{N}$ ve $\mathrm{NO}_{2}-\mathrm{N}$ analizleriyle gerçekleştirilmişstir. Yapılan analizler sonucunda elde edilen azot bileşikleri konsantrasyonları Tablo 3'de özetlenmiştir.

Tablo 3. Bardenpho Prosesinin her bölmesinde azot bileşiklerinin konsantrasyonlarının değişimi ve elde edilen giderim verimleri

\begin{tabular}{|c|c|c|c|c|c|c|}
\hline & $\begin{array}{l}\mathrm{NH}_{3}-\mathrm{N} \\
(\mathrm{mg} / \mathrm{L})\end{array}$ & $\begin{array}{c}\text { Ort. } \\
\text { (mg/L) }\end{array}$ & $\begin{array}{l}\mathrm{NO}_{2}-\mathrm{N} \\
(\mathrm{mg} / \mathrm{L})\end{array}$ & Ort. (mg/L) & $\begin{array}{l}\mathrm{NO}_{3}-\mathrm{N} \\
(\mathrm{mg} / \mathrm{L})\end{array}$ & $\begin{array}{c}\text { Ort. } \\
\text { (mg/L) }\end{array}$ \\
\hline Giriş & $9,0-4,4$ & 5,11 & $0,07-0,01$ & 0,026 & $3,3-2,0$ & 2,49 \\
\hline Anaerobik & $9,2-5,4$ & 7,44 & $0,12-0,04$ & 0,041 & $3,0-0,8$ & 1,79 \\
\hline 1.Anoksik & $9,4-4,1$ & 6,82 & $0,12-0,010$ & 0,040 & $2,6-0,7$ & 1,65 \\
\hline 1.Aerobik & $10,8-0,8$ & 4,33 & $0,09-0,009$ & 0,040 & $3,0-0,6$ & 1,70 \\
\hline 2.Anoksik & $11,5-2,3$ & 6,95 & $0,09-0,009$ & 0,042 & $3,0-0,8$ & 2,02 \\
\hline 2.Aerobik & $12,0-0,5$ & 4,56 & $0,09-0,004$ & 0,044 & $2,8-0,8$ & 1,80 \\
\hline Çıkış & $3-0,5$ & 1,44 & $0,02-0,003$ & 0,006 & $1,1-0,8$ & 0,80 \\
\hline Verim (\%) & $60-95$ & 75 & $65-90$ & 71 & 50-83 & 66,7 \\
\hline
\end{tabular}

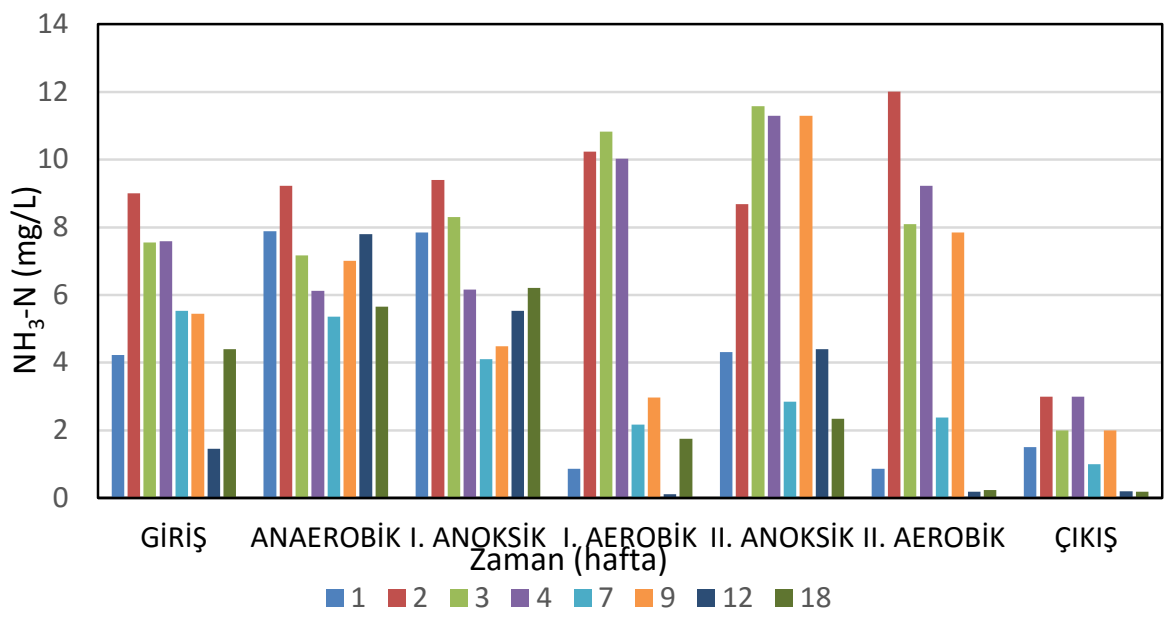

Şekil 4. $\mathrm{NH}_{3}-\mathrm{N}$ konsantrasyonlarının Bardenpho Prosesi boyunca değişimi 


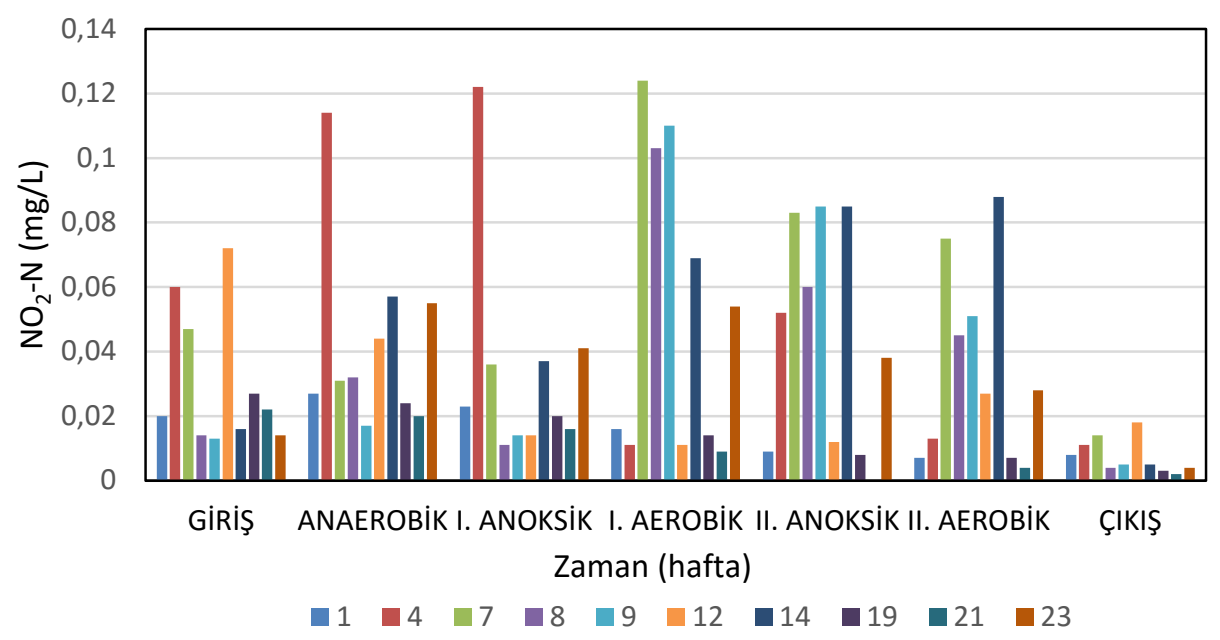

Şekil 5. $\mathrm{NO}_{2}-\mathrm{N}$ konsantrasyonlarının Bardenpho Prosesi boyunca değişimi

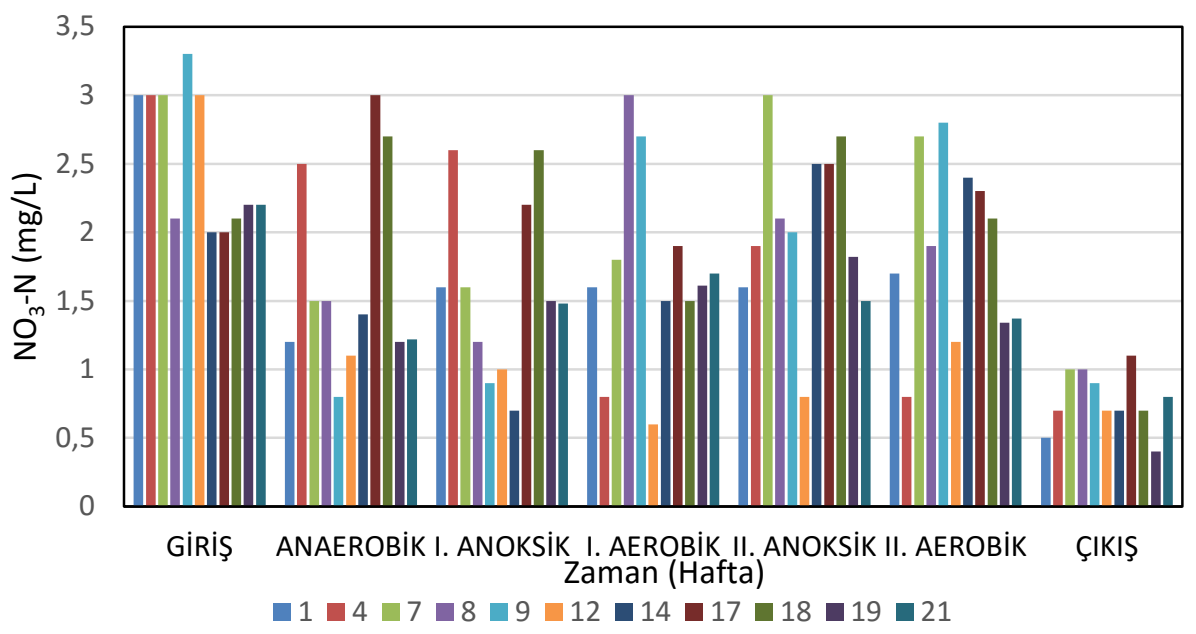

Şekil 6. $\mathrm{NO}_{3}-\mathrm{N}$ konsantrasyonlarının Bardenpho Prosesi boyunca değişimi

Sistemin azot giderimini kontrol etmek için $\mathrm{NH}_{3}-$ $\mathrm{N}$ analizleri de yapılmış ve giriş çıkıș konsantrasyonları ile giderim verimleri Şekil 4'te gösterilmiş̧ir. $\mathrm{NH}_{3}-\mathrm{N}$ konsantrasyonunun genel olarak anaerobik fazda hafif bir yükselme eğiliminde olduğu, özellikle II. aerobik fazda düştüğü görülmüş olup bu durum aerobik ortamda nitrifikasyon bakterilerinin amonyağı nitrit ve nitrata dönüştürmelerinden kaynaklanmaktadır. Anoksik ortamda $\mathrm{NH}_{3}-\mathrm{N}$ konsantrasyonunda anaerobik faza göre önemli bir değişim olmamıștır. Amonyak ortam pH'ına bağlı olarak uçucu bir gaz olduğundan sistemin amonyak ölçüm verileri nitrifikasyon ve denitrifikasyon takibini yapmak için çok net sonuçlar göstermemiştir. Bu sebeple amonyak yerine toplam azot verisinin takibinin daha hassas olacağ 1 sonucuna varılmıștır. Nitrit ve nitrat azotu derişimlerinin prosesin bölmelerine bağlı değişimleri Şekil 5 ve 6 'da verilmiştir. Sistemde nitrit konsantrasyonlarının anaerobik ve anoksik reaktörlerde önemli bir değişim göstermediği nitrifikasyona bağlı olarak özellikle II. Aerobik fazda artış gösterdiği görülmüştür. Nitrat derişimleri ise girișe göre anaerobik ve anoksik fazlarda bir düşüş göstermiş, II. Anoksik fazda ne bir düşüş gözlenmezken II. Aerobik fazda aynı seviyede devam etmiştir. Çöktürme tankı olarak kullanılan çıkış bölmesinden çıkan çıkış suyunda ise 1 ppm'in altında değerlere düşmüş ve toplamda $\% 80$ giderim elde edilmiştir.

\subsection{Fosfor Giderimi}

Bardenpho prosesinin fosfor giderim performansını incelemek için numunelerde $\mathrm{PO}_{4}-\mathrm{P}$ analizleri yapılmıştır. Elde edilen sonuçlar Tablo 4'te özetlenirken giriş atıksuyu ve reaktör çıkışı arasındaki konsantrasyonları Sekil 7'de gösterilmiștir. Daha önce de belirtildiği gibi reaktör dört ay boyunca işletilmiş olup KOİ ve $\mathrm{N}$ sonuçlarındakine benzer şekilde reaktörün performans $1 \mathrm{PO}_{4}-\mathrm{P}$ giderim veriminde de zamanla iyileşmiş buna bağlı olarak çıkış suyu $\mathrm{PO}_{4}-\mathrm{P}$ konsantrasyonları hedeflenen değerlere düșmüștür. Sistemde fosfor derişimi PAO'ların fosforu açığa çıkarmaları nedeniyle anaerobik fazda giriş suyuna göre yükselme göstermiş, devamında prosesin farklı 
bölmelerinde çıkışa doğru her bölmede sürekli bir fosfor giderimi meydana gelmiştir. Akın ve Uğurlu anoksik fazın $\mathrm{P}$ giderimine etkisi üzerindeki çalışmalarında, bu fazın fosfor giderim verimini yaklaşık $\% 15$ oranında artırdığını belirtmişlerdir[12]. Anoksik fazda PAO'lar nitrat azotunu elektron alıcısı olarak kullanmakta olup, böylece depo ürünlerinin oksidasyonuyla bünyelerine $\mathrm{P}$ alarak arıtım sağlamaktadırlar. $\mathrm{Bu}$ sebeple çalışmada anoksik ve aerobik fazların ardışık olarak bulunması yüksek fosfor gideriminin sağlanmasında etkili olmuştur.

Tablo 4. Reaktörün $\mathrm{PO}_{4}$-P konsantrasyonları ve elde edilen verimler

\begin{tabular}{|c|c|c|}
\hline & PO $\left._{\mathbf{4}} \mathbf{- P} \mathbf{( m g} / \mathbf{L}\right)$ & Ortalama \\
\hline Giriş & $10,2-7,9$ & 9,2 \\
\hline Anaerobik & $13,2-11,1$ & 12,2 \\
\hline 1.Anoksik & $8,1-6,5$ & 7,1 \\
\hline 1.Aerobik & $5,7-4,2$ & 4,9 \\
\hline 2.Anoksik & $6,1-5$ & 5,5 \\
\hline 2.Aerobik & $4,6-4$ & 4,3 \\
\hline Çıkıș & $4,6-3$ & 3,9 \\
\hline Verim (\%) & $70,6-50,6$ & 56,7 \\
\hline
\end{tabular}

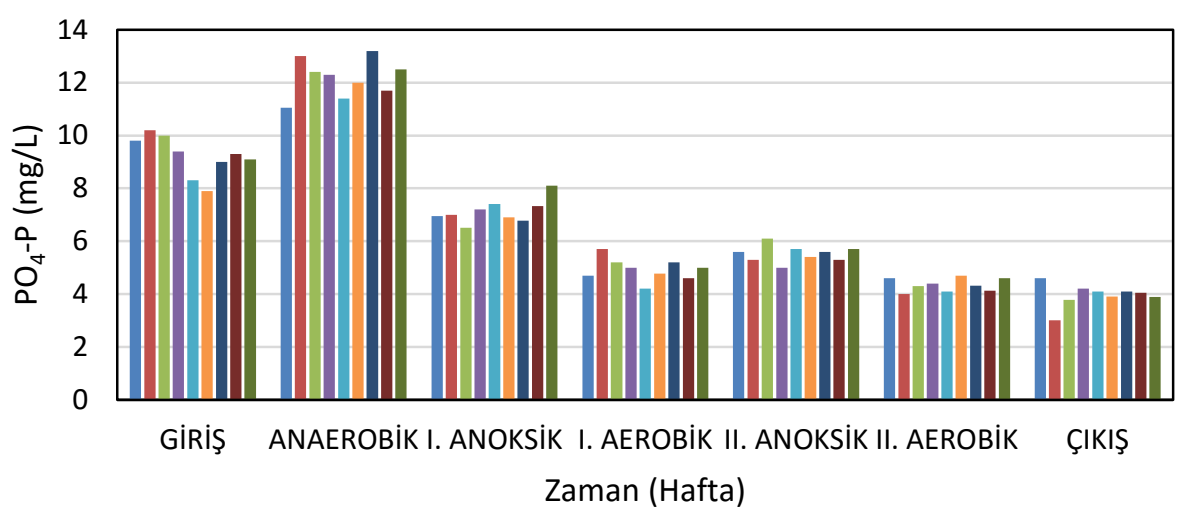

घ $1 \square 2 \square 3 \square 4 \square 5 \square 6 \square 7 \square 8 \square 9$

Şekil 7. $\mathrm{PO}_{4}-\mathrm{P}$ konsantrasyonlarının Bardenpho Prosesi boyunca değişimi

\section{SONUÇ}

Atıksularda bulunan azot ve fosfor gibi besin elementlerinin yeterince aritılmadan alıcı ortamlara deşarj edilmesi, bu doğal su ortamlarında ötrofikasyon adı verilen kötü koku, renk oluşumu, oksijen tüketimi, bataklık görünümü gibi istenmeyen şartların oluşmasına neden olmaktadır. Bu olumsuz şartlar özellikle durgun su ortamlarında daha belirgin şekilde ortaya çıkmakta, bu ortamlardaki doğal ekolojik hayatın akışını olumsuz yönde etkilemektedir. Bu olumsuz etkileri gidermek ve daha verimli sonuçlar almak amacıyla atıksulardan organik maddelerin yanı sira azot ve fosfor bileşiklerinin giderimi için yeni prosesler geliştirilmektedir. Bu proseslerden biri de çalışmada kullanılan Beş Basamaklı Bardenpho prosesidir. GASKI İleri Biyolojik Atıksu Arıtma Tesisinin havalandırma havuzundan ve kum tutucu çıkışından alınan aktif çamur ile işletime alınan sistem dört ay boyunca beslenmiş ve arıtım performansı takip edilmiştir. Elde edilen verimler literatür verileri ile karşılaştırıldığında sistemin iyi bir biyolojik arıtım ve nütrient giderimi gerçekleştirdiğini göstermiştir. Diğer taraftan elde edilen sonuçlar ülkemizde yürürlükte olan "Kentsel Atıksu Arıtımı Yönetmeliği” ve "Su Kirliliği Kontrolü Yönetmeliği” hükümlerinin yerine getirilmesi için sistemin iyi bir arıtma alternatifi olabileceğini ortaya koymuştur.

\section{TEŞEKKÜR}

Bu çalışma KSÜ-BAP Birimi tarafından desteklenen 2014/2-11 LAP nolu Proje verilerinden oluşturulmuştur. Çalışmanın yürütülmesinde sağladığı finansal desteğinden dolayı KSÜ-BAP birimine teşekkür ederiz.

\section{KAYNAKLAR}

[1]. Samsunlu. A.. (2006). "Atık Suların Arıtılması". 3.bask1, Birsen Yayınevi, İstanbul 
[2]. Ayrak. B.. (2010). "Evsel Atıksuların Arıtılması ve Maliyet Analizi”. Gebze Yüksek Teknoloji Enstitüsü Mühendislik ve Fen Bilimleri Enstitüsü, Yüksek Lisans Tezi

[3]. Yıldırım. A.. (2012). "Evsel Atıksulardan Modifiye Beş Basamaklı Bardepho Prosesiyle Nütrient Giderimi ve Bulanık Mantık Yönteminin Uygulanması". Yıldız Teknik Üniversitesi. Fen Bil. Ens., Çevre Mühendisliği ABD, Yüksek Lisans Tezi.

[4]. Balçık Ç. (2012). "Evsel Atıksulardan Nitrüent Gideriminde Pilot Ölçekli Bardenpho ile Kaskat Proseslerinin Karşılaştırılması”. Yıldız Teknik Üniversitesi. Fen Bil. Ens., Çevre Mühendisliği ABD, Yüksek Lisans Tezi.

[5]. Pagilla. K.R.. Urgun-Demirtas. M.. Ramani. R.. (2006). "Low effluent nutrient technologies for wastewater treatment”. Water Sci. Technol, 53 (3): 165-172

[6]. Pehlivanoglu-Mantas. E.. Sedlak. D.L.. (2004). "Bioavailability of wastewater-derived organic nitrogen to the alga Selenastrum capricornutum. Water Res”, 38 (14-15): 3189-3196.

[7]. Aquino. S.F.. Stuckey. D.C.. (2003). "Production of soluble microbial products (SMP) in anaerobic chemostats under nutrient deficiency”. J. Environ. Eng, 129 (11): 10071014.

[8]. Barker. D.J.. Stuckey. D.C.. (1999). “A review of soluble microbial products (SMP) in wastewater treatment systems”. Water Res, 33 (14): 3063-3082.

[9]. Korkusuz. E.A.. Beklioğlu. M. ve Demirer. G.N.. (2005). "Comparison of the treatment performances of blast furnace slag-based and gravel-based vertical flow wetlands operated identically for domestic wastewater treatment in Turkey”. Ecological Engineering, 24(3): 187-200.

[10]. James. L. Barnard. P.. Stephen. A. (2005). "Biological Nutrient Removal (BNR) Operation Wastewater Treatment Plants”. s. 165.

[11]. Peng. Y.. Wang. X. ve Li. B.. (2006). “Anoxic Biological Phosphorus Uptake and the Effect of Excessive Aeration on Biological Phosphorus Removal in the $\mathrm{A}^{2} \mathrm{O}$ Process". Desalination, 189(1-3):155-164

[12]. Akın. B.S. ve Uğurlu. A.. (2004). "The Effect of an Anoxic Zone on Biological Phosphorus Removal by a Sequential Batch Reactor". Bioresource Technology, 94(1):1-7 